\title{
Efficacy of Percutaneous Vertebroplasty in the Treatment of Malignant and Benign Vertebral Fractures: Single-Center Experiences
}

\author{
Mehmet Fatih Inecikli,® Bahattin Hakyemez ${ }^{1}$ \\ ${ }^{1}$ Department of Radiology, Bursa Uludag University School of \\ Medicine, Bursa, Turkey
}

J Clin Interv Radiol ISVIR 2021;5:72-78.
Address for correspondence Mehmet Fatih Inecikli, Department of Radiology, Bursa Uludag University School of Medicine, Bursa, Turkey (e-mail: drmfinecikli@uludag.edu.tr).

\begin{abstract}
Keywords

- vertebroplasty

- vertebral fracture

- pain treatment

Percutaneous vertebroplasty (PVP) is a method used for vertebral stabilization and pain treatment. This study was performed to demonstrate the efficacy of PVP in treatment of malignant and benign vertebral compression fractures (VCFs). The study was conducted on 45 cases with a total of 106 VCFs. The mean age of the patients was 62.4 years (37-86 years). The vertebral fractures were classified according to Genant's Classification. Pain was rated using the visual analog scale (VAS). VAS scores were recorded before and after PVP operations. A total of 58 vertebrae (54.8\%) were treated via a bipedicular approach, and 48 vertebrae (45.2\%) were treated via a unilateral transpedicular approach with the help of biplane imaging and under anesthesia. L1 vertebra (19.8\%) fractures and Grade III fractures (46.3\%) were more common. Vertebral collapse was the most common cause of malignancy (53.8\%). The mean VAS score was measured to be 8.39 before the VP operations and 2.05 after the VP operations. The VAS score dropped to 2.3 through the unipedicular approach and to 1.84 through the bipedicular approach. The decrease in pain due to VP was statistically significant $(p<0.001)$. There was no statistically significant difference between the unipedicular and bipedicular approaches in terms of pain relief ( $p>0.05)$. Some patients (18.8\%) had complications. PVP is a highly therapeutic method for pain relief in case of pain secondary to malignant or benign vertebral fractures.
\end{abstract}

\section{Introduction}

Percutaneous vertebroplasty (PVP) is a minimally invasive method for the treatment of malignant or benign VCFs, which is performed while using image guiding. Using the PVP procedure, the weakened vertebral body is filled with bone cement to strengthen the spine and reduce pain. Our aim in this study was to demonstrate the efficacy of PVP in benign and malignant VCFs. The main causes of VCFs include falling from a height, traffic accidents, sports injuries, and

published online May 17, 2021
DOI https://doi.org/

$10.1055 / \mathrm{s}-0041-1729777$ ISSN 2457-0214 primary pathologies in the vertebrae (tumors, infections, osteoporosis, or metabolic bone diseases). Osteoporosis is the most common cause of VCFs. ${ }^{1}$ VCFs may also develop as fractures that are secondary to malignancies. The most common causes of spinal metastasis are breast, lung, prostate, thyroid, and renal cancers. ${ }^{2,3}$ Pain is often the first symptom and a significant cause of morbidity that limits quality of life. ${ }^{3}$ Roentgenography (RG) is the first step in imaging methods. Computed tomography (CT) and magnetic resonance imaging (MRI) are important for detecting the causes

(C) 2021. Indian Society of Vascular and Interventional Radiology. This is an open access article published by Thieme under the terms of the Creative Commons Attribution-NonDerivative-NonCommercial-License, permitting copying and reproduction so long as the original work is given appropriate credit. Contents may not be used for commercial purposes, or adapted, remixed, transformed or built upon. (https://creativecommons.org/licenses/by-nc-nd/4.0/). Thieme Medical and Scientific Publishers Pvt. Ltd. A-12, 2nd Floor, Sector 2, Noida-201301 UP, India 
of a fracture and anatomically identifying its type. Increased intensity in fat-suppressed T2-weighted (T2W) and short tau inversion recovery (STIR) sequences indicates bone marrow edema. ${ }^{4}$ The logic behind the main mechanism for how a PVP procedure eliminates pain is thought to be the effect of polymethylmethacrylate (PMMA). PMMA causes heat damage in nociceptors while it polymerizes, and it causes chemotoxicity in intraosseous pain receptors. Additionally, mechanical stabilization reduces pain. ${ }^{5}$ VCFs frequently occur in the thoracolumbar junction (T11-L2) and in the middle of the thoracic region (T7-T8). ${ }^{6}$ VCFs usually result in the collapse of the vertebrae, which is accompanied by pain. ${ }^{7}$ VCFs are graded according to Genant's Classification ${ }^{8}$ and considered to fall into three headings. Grade I: 20 to $25 \%$ loss in the height of the vertebral body; Grade II: 26 to $40 \%$ loss in the height of the vertebral body and Grade III: more than $40 \%$ loss in the height of the vertebral body. VAS is a line that is usually $10-\mathrm{cm}$ long, starting with "no pain" and ending with "excruciating pain." ${ }^{-11}$

\section{Materials and Methods}

This study was conducted in patients diagnosed with malignant or benign VCFs based on physical and radiological examinations who were selected from among patients admitted to clinics for back pain. A multidisciplinary approach was applied. Clinical evaluations and related tests were performed. Laboratory data and radiological findings were evaluated together. In cases where malignancy was suspected, before the PVP procedure, bone biopsy was performed via core biopsy or the drilling method with a transpedicular approach. All cases were proven pathologically. All medical records were retrospectively analyzed. Age, sex, mechanism, and risk factors for the VCFs were recorded. The causes and levels of vertebral collapses, methods of PVP access methods, complications during the procedure, and VAS scores in the pre- and postoperative periods were investigated. Patients with VCFs and PVP indications were managed by the Department of Radiology (Interventional Radiology). In our study, the inclusion criteria were as follows: Written consent, the absence of bleeding diathesis, not being pregnant, not having any sepsis, the presence of vertebral body height loss on RG or CT examinations, T1W hypointensity in the vertebral body on MRI and hyperintensity in T2W and STIR images, the absence of vertebra plana (the collapse of more than $80 \%$ of the vertebral height) and to reduce pain, having no medical treatment for at least 1 month and having no favorable results. If there were an advanced VCF due to a primary or secondary malignancy, the patient had to undergo antineoplastic therapy, radiotherapy, or other necessary treatment modalities in the appropriate period of time. The exclusion criteria were as follows: not signing the consent form, the presence of bleeding diathesis, being pregnant, having sepsis, not having any loss of vertebral body height on RG or CT examinations, having hypointensity in T1W and T2W images in the vertebral body on MRI, having vertebra plana or undergoing medical treatment for less than a month. The diagnostic radiological examinations of the patients consisted of $\mathrm{RG}, \mathrm{CT}$, and MRI. The follow-up period was determined as 1 year for each patient. In the event that pain developed as a result of vertebral fractures caused by primary or metastatic tumors, painkillers were primarily used to reduce pain. Moreover, treatment methods such as chemotherapy, radiotherapy, and/or immunotherapy were administered if necessary. If the patient still suffered from pain even after these methods, vertebroplasty was implemented. The PVP procedure was performed on 106 vertebrae in 45 patients. However, 30 of the patients included in the study were male and 15 were female. The main age of the patients was 62.4 years (37-86 years). VCFs were graded according to Genant's Classification. Detailed anatomical examinations were performed based on CT and MRI, and concomitant secondary pathologies were analyzed. There was hyperintensity indicating bone marrow edema on the T2W and STIR levels on the vertebral body (-Fig. 1). Most VCFs were malignant (primary or metastatic). Multiple myeloma was the most common cause of the malignant VCFs. This was followed by metastatic lesions (-Fig. 2). The patients also underwent PVP for their osteoporotic and traumatic VCFs (-Fig. 3). All cases were checked through appropriate examinations for eligibility for the PVP procedure prior to the procedure. A consent form was filled out by each patient. All treatment procedures were performed in the angiography suit by using a biplane angiography device (Axiom Artis, Siemens, Erlangen, Germany). Prior to the operation, each patient was intravenously given $1 \mathrm{~g}$ of cefazolin sodium (Cefazolin for Injection, Sandoz, Canada) for antibiotic prophylaxis. For sedoanalgesia, the following medicines were intravenously administered by anesthesiologists: Midazolam $1 \mathrm{mg} / \mathrm{mL}$ (Dormicum, Roche, Switzerland) at a dose of $0.1 \mathrm{mg} / \mathrm{kg}$ and fentanyl citrate $50 \mu \mathrm{g} / \mathrm{mL}$ (Fentanyl Citrate Injection USP, Sandoz, Canada) at a dose of 1 to $2 \mu \mathrm{g} / \mathrm{kg}$. All patients were placed on the operating table in a prone position. The patients were operated using a unilateral or a bilateral transpedicular approach. The decision was made on the basis of the distribution of the PMMA within the
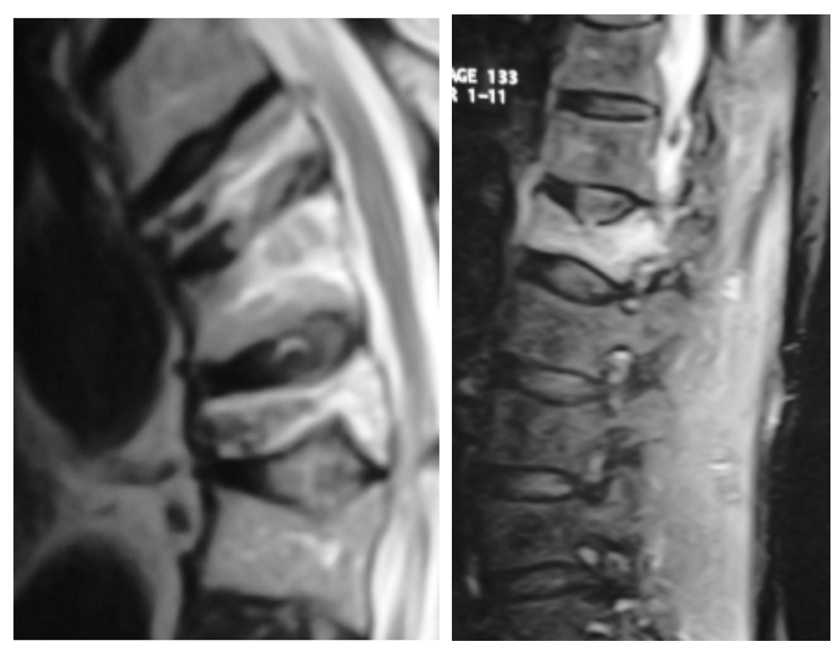

Fig. 1 Presence of increased intensity consistent with edema corresponding to acute vertebral fractures is observed in the T2-weighted and short tau inversion recovery sequences in the magnetic resonance imaging. 


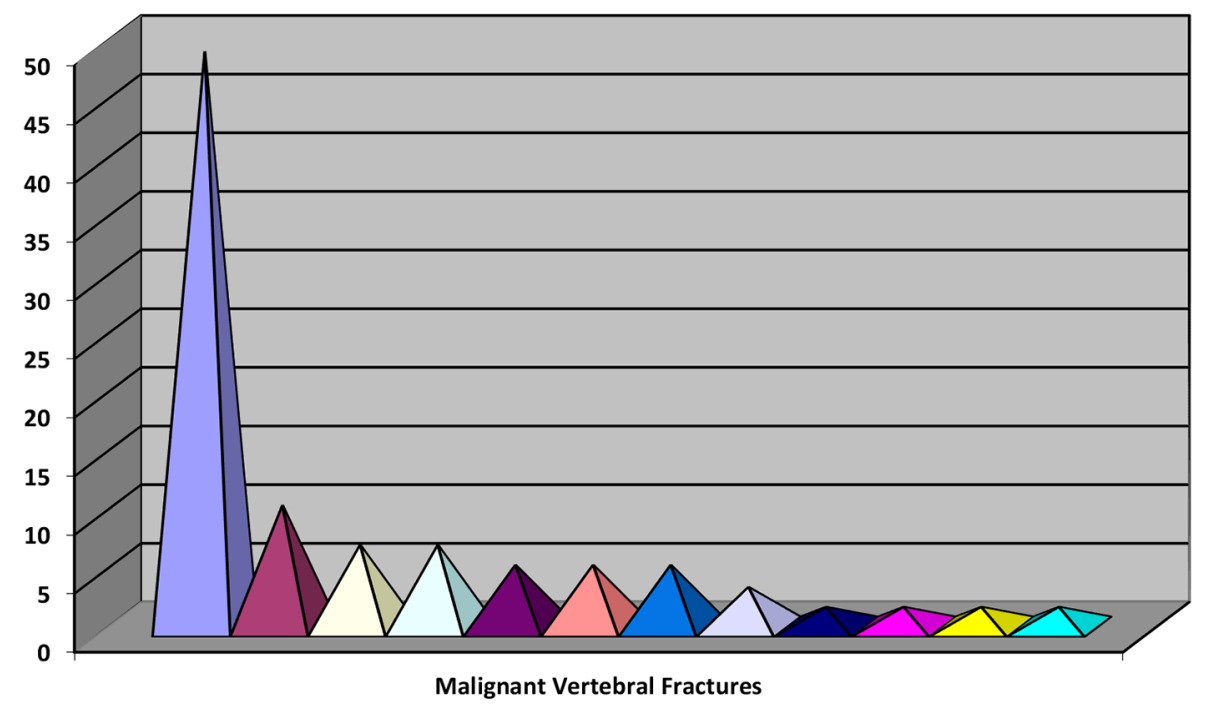

\begin{tabular}{|c|c|c|c|}
\hline 口Malignant Melanoma & 口Breast Cancer & 口Lung Cancer & 口Endometrial Carcinoma \\
\hline 口Prostate Cancer & 口Colon Cancer & 口Lymphoma & 口Stomach Cancer \\
\hline Denal Cell Cancer & 口Laryngeal Cancer & 口Pancreatic Cancer & 口Ovarian Cancer \\
\hline
\end{tabular}

Fig. 2 Distribution of malignant vertebral fractures within themselves.

\begin{tabular}{|c|c|c|}
\hline Causes of Vertebral Fractures & $\begin{array}{c}\text { Level Undergoing } \\
\text { Vertebroplasty }\end{array}$ & Rate \\
\hline Malignant vertebral collapse & 57 & $53.8 \%$ \\
\hline Osteoporotic & 41 & $38.7 \%$ \\
\hline Traumatic & 8 & $7.5 \%$ \\
\hline TOTAL & $\mathbf{1 0 6}$ & $\mathbf{1 0 0 \%}$ \\
\hline
\end{tabular}

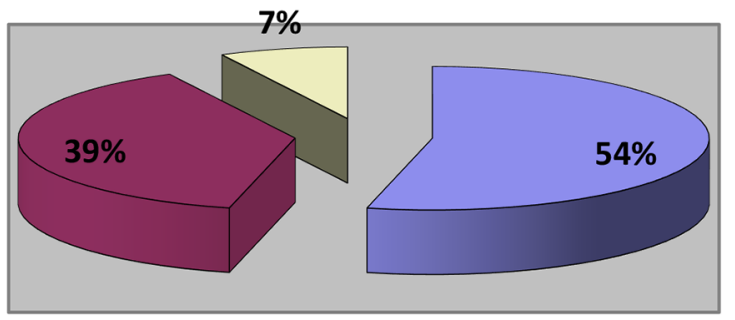

\section{$\square$ Malignant $\square$ Osteoporotic $\square$ Traumatic}

Fig. 3 Causes of vertebral fractures.

vertebral body. If the PMMA did not spread from the midline of the vertebral body to the opposite side with the unipedicular approach, the bipedicular approach was preferred. The vertebral pedicle was reached through the appropriate angle by using an $11 \mathrm{G}$ bone access needle (Angiotech Medical Devices, Florida, United States). With the help of a hammer, the needle was inserted up to $1 / 3$ of the posterior section of the vertebral body. The needle was pulled, and a guidewire (Kirschner wire) was inserted from inside the cannula. A working cannula system (Kyphon Inc., Sunnyvale, California, United States), which is a coaxial system, was placed through the guidewire. A precision drill was placed to the vertebral body from inside the cannula, and a cavity was created within the vertebral body by drilling. For the bipedicular approach, 
another cannula was inserted from the other pedicle. We preferred high-viscosity radiopaque bone cement (KyphX HV-R Elmdown Ltd., London, UK). Most high-viscosity cements have short fluid blending phases and allow longer working times. The dough time of PMMA takes 2 to 3 minutes after the mixing of the powder and liquid, and 7 to 12 minutes to complete fixation. Once the cement reached the proper viscosity, it was drawn into a 20 -cc injector. The cement was then filled into a cannula with a $1.5 \mathrm{cc}$ capacity (Bone Filler Device, Kyphon Inc., Sunnyvale, California, United States). The cement was injected into the corpus beginning at the 4 to 5 th minute (the viscosity of toothpaste fluidity) and completed within 11 minutes at the latest. In general, the cement injection was terminated when the cement reached $2 / 3$ of the anterior part of the vertebral body and the inferior-superior end-plate and when the cement exceeded the midline of the vertebral body. Crossing the midline can be used as a technical success point but not as an end point. One should allow as much anterior spread of cement on each side as possible. Once the procedure was completed, the patients were discharged after 2 hours of bed rest. Generally, PVP was performed on one vertebral body. However, in patients with multiple VCFs, two or three VCFs were treated in one session. In case of fractures on the 4 to 10 th vertebral levels, PVP treatments were preferred to be administered in different sessions. The patients were asked to come for face to face follow-ups at 1 week, 1,3 , and 6 months and 1 year after the PVP operation. The pain severity was recorded by using VAS scores. The VAS scores were analyzed before and after the PVP procedure. Statistical analysis of the data was conducted in the Statistical Package for the Social Sciences for Windows 13.0 (SPSS Inc., Illinois, United States) software. Mean, standard deviation, median, minimum, and maximum values were measured for the pain scores. Wilcoxon Rank Total Test was used for intragroup comparisons. The pre-PVP and post-PVP values were compared for inter-group comparisons through Mann-Whitney-U Tests. In the study, $p<$ 0.05 was considered statistically significant.

\section{Results}

The cement was injected through a unilateral transpedicular approach into 48 vertebrae (45.2\%) and through a bipedicular approach into 58 levels (54.8\%). Multiple sessions of PVP were performed on 13 patients. The maximum number of levels PVP was performed on a single patient was 10. It was administered in four sessions. The level on which PVP was performed at the most proximal part of the vertebral column was T6. The vertebral level most frequently undergoing PVP operations was the L1 vertebra with 21 cases (19.8\%). During the PVP procedures, 20 levels (18.8\%) had complications including paravertebral venous leakage, leakage into the disc space, and paravertebral soft tissues and pulmonary embolism. The most common of these was paravertebral venous leakage (35\%). Some of the complications that developed during the PVP procedures are presented in - Fig. 4. At 1-year follow-up after the PVP procedures,

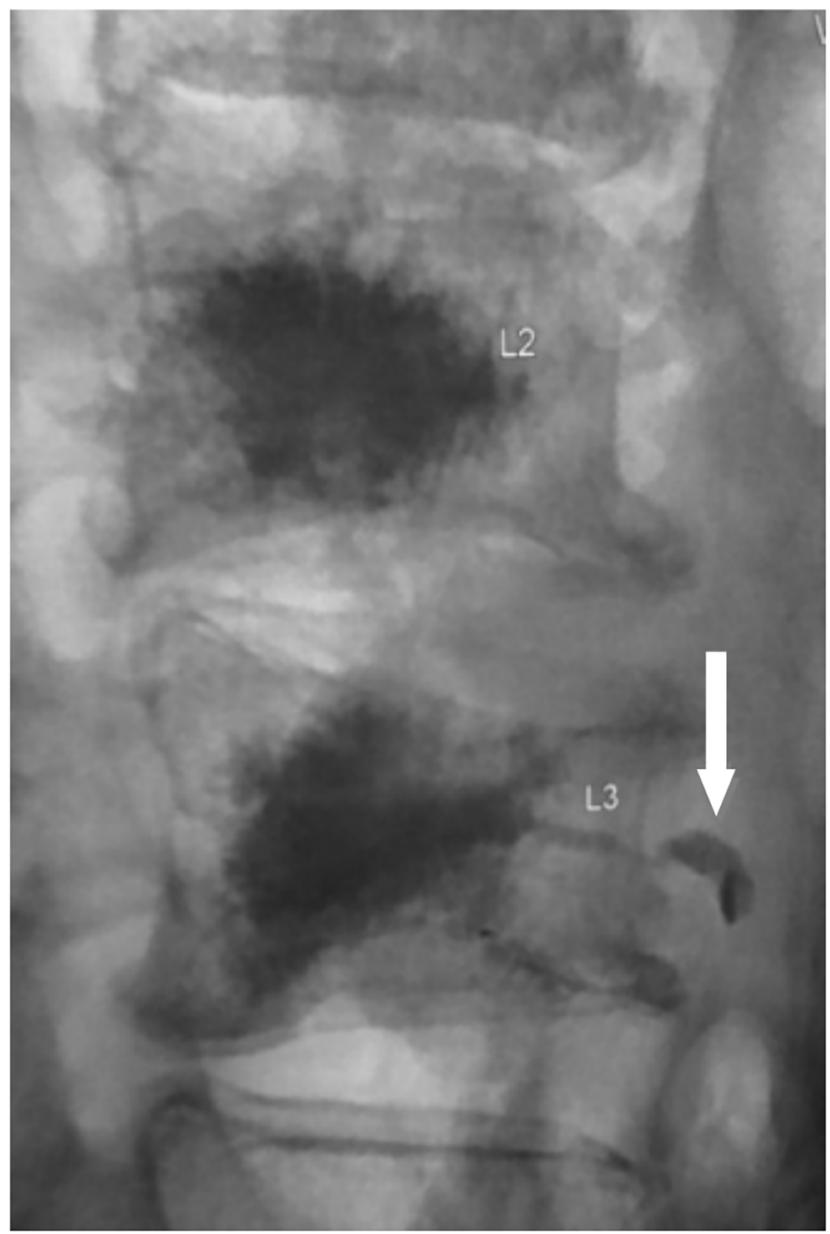

Fig. 4 Cement leakage into paravertebral venous structures (white arrow).

the mean VAS score of all patients was $8.39 \pm 0.07$ before PVP and $2.05 \pm 0.01$ after PVP. The median value before PVP was 8.0 , while the minimum value was 7.0 , and the maximum value was 10.0. The median value after PVP was 2.0, while the minimum value was 1.00 , and the maximum value was 5.00. There was a statistically significant difference in the VAS scores after the PVP procedure in comparison to those before the PVP procedure $(p<0.001)$. - Fig. 5 provides data before and after vertebroplasty in a patient with a vertebral fracture. In the unipedicular approach, the mean VAS score was 8.39 before PVP and 2.30 after PVP. Prior to the procedure, the standard error, median, minimum, and maximum values were calculated as $0.105,8.0,7.0$, and 10.0 , respectively. After the procedure, these values were 0.16 , $2.0,1.00$, and 5.00, respectively. In the bipedicular approach, the mean VAS score was 8.38 before PVP and 1.84 after PVP. Prior to the procedure, the standard error, median, minimum, and maximum values were calculated as $0.093,8.0$, 7.0 , and 10.0, respectively. After the procedure, these values were $0.13,2.0,1.00$, and 5.00 , respectively. No significant difference was found regarding the efficacy of the unipedicular and bipedicular approaches on pain reduction $(p>0.05)$. - Fig. 6 shows the differences in the VAS scores between the unipedicular and bipedicular approaches. 


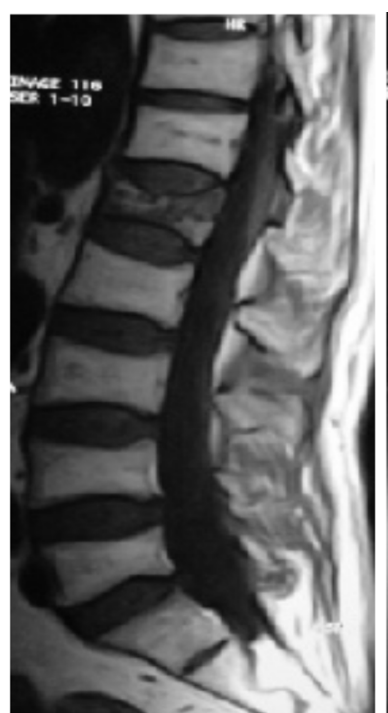

A

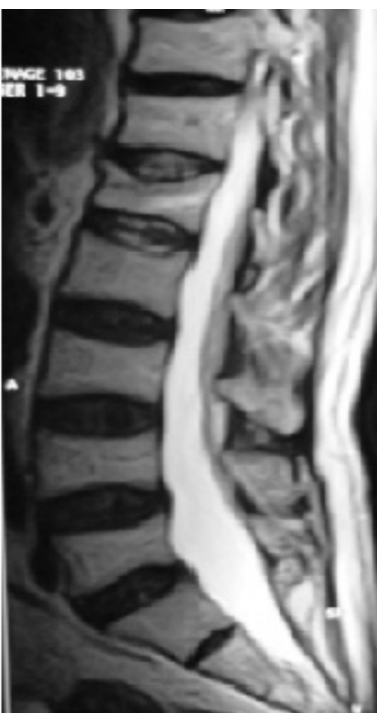

B

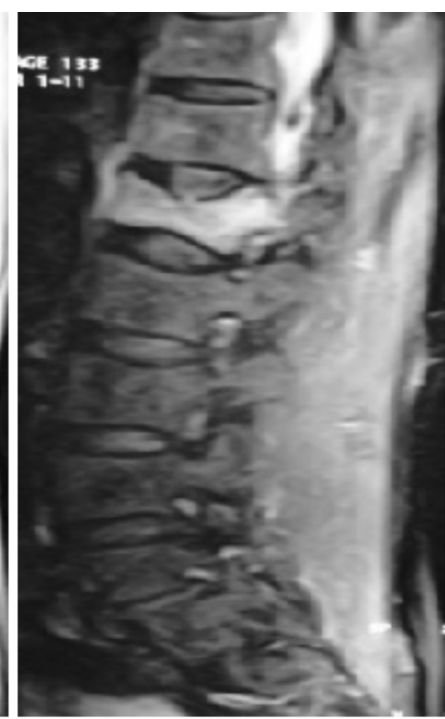

C

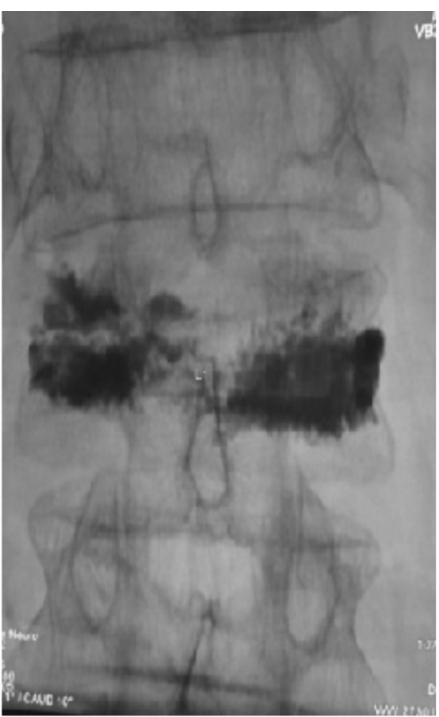

D

Fig. 5 A 70-year-old male patient with prostate cancer. There is a metastatic $L_{1}$ vertebral fracture. There is a complaint of severe low back pain. (A) Grade III fracture at the $\mathrm{L}_{1}$ vertebra. T1-weighted sagittal image shows hypointensity. (B) T2-weighted sagittal image shows slight hypointensity. (C) Diffuse edema signs in the bone marrow, which are an indication of an acute fracture, draw attention in the short tau inversion recovery image. (D) Vertebroplasty (VP) was performed via a bipedicular approach. A-P graphy after VP. The visual analog scale score was recorded to be 10 before the VP and 1 after the VP.

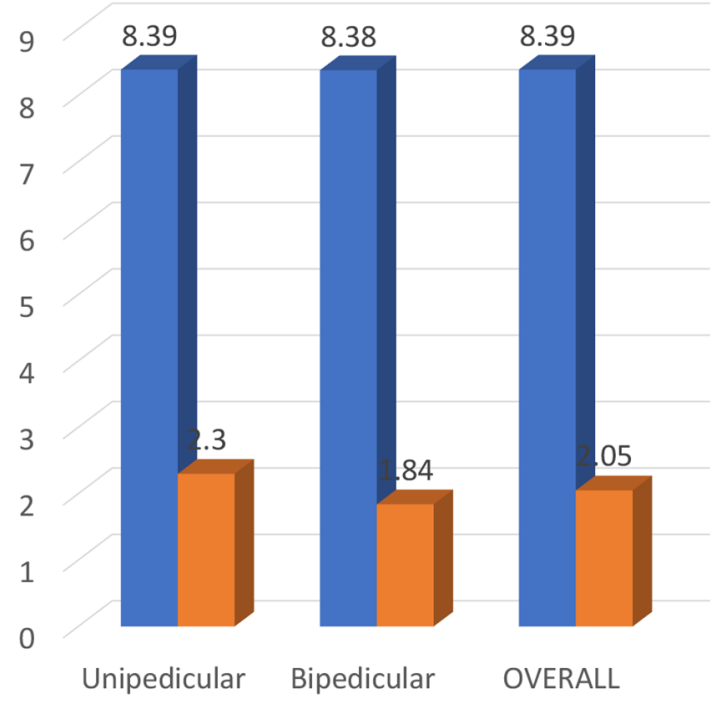

-VAS Score before VP $\quad$ VAS Score after VP

Fig. 6 Changes in visual analog scale scores based on different approaches.

\section{Discussion}

The PVP procedure is performed to improve vertebral resistance and reduce pain by filling the weakened vertebral body with bone cement. Patient selection is a factor that affects the success of PVP operations. Benyamin and Vallejo ${ }^{12}$ reported that physical examination and direct RG examination are the first steps in patient selection, and fractures and vertebral edema should be detected in T2W sequences in MRI. Mckiernan et a ${ }^{13}$ stated that changes in characteristic signal intensity showing the fracture age can be detected by using MRI in VCFs. In our study, all patients underwent RG and MRI examinations, and suitable cases were included in the study. Osteoporosis is the most common cause of VCFs. ${ }^{14,15}$ Another important reason is malignancy-induced VCFs. Lytic lesions caused by metastatic vertebral involvement cause not only pain but also fractures and instability. Such instability may be significant with deterioration in the integrity of the vertebral column, as well as potential instability, which initially appears to be asymptomatic but manifests itself by minor trauma. ${ }^{16}$ In our study, malignant vertebral collapses with a rate of $53.8 \%$ were found to be the most frequent cause of vertebral fractures. Among the primary malignant causes, multiple myeloma was the most frequently observed cause with an incidence rate of $26.4 \%$. Breast cancer metastasis was the number one cause of metastatic vertebral collapses (5.6\% of all patients and $10.5 \%$ of patients with malignancy). Osteoporosis has frequently been identified as the cause of VCFs in many studies. However, it was the second most frequent cause in our patients with a rate of $38.7 \%$. The reason for this may have been the fact that the patients who were referred to us were sent from different disciplines (more patients were sent from the hematology and oncology clinics). The recommended method for the PVP operation is local anesthesia supported by conscious sedation. ${ }^{17,18}$ We preferred local anesthesia and sedoanalgesia in our study, too. PVP may be performed using a unipedicular or bipedicular approach. These methods were compared in a biomechanical study on a cadaver vertebra, ${ }^{19}$ and in a study involving unipedicular injection, the cement injected just enough to exceed 
the midline was shown to offer sufficient strength and not cause any complications. ${ }^{20}$ The volume of cement injected that does not exceed the central vertical axis of the vertebral body should not be considered biomechanically adequate. If the cement only spreads to one side of the vertebral body, cement should be injected from the other side. In our series, the bipedicular approach (54.8\%) was used more often than the unipedicular approach (45.2\%). The PVP procedure was completed in one session at a rate of $71 \%$. However, a second session of PVP was performed on $24.6 \%$ of the patients, and a third session was applied on $4.4 \%$. The ideal biomaterial as bone cement in PVP operations should be injectable, easy to apply, have appropriate fluidity, high radiopaque properties, long hardening time, and be cost-effective. PMMA is widely used all over the world. The appropriate amount of PMMA that can be injected into the vertebral body varies between 3 and $8 \mathrm{~mL}$. Mehbod et $\mathrm{a}^{21}$ emphasized that, depending on the type and amount of bone cement, there should be bone cement corresponding to $15 \%$ of the volume of the vertebra requiring restoration. It was stated that the vertebra will have the desired stiffness with the use of $3.5 \mathrm{~mL}$ of bone cement. Heini et $\mathrm{a}^{22}$ stated that bone cement injections that are less than the required amounts cause recurrent fractures. They reported in their study that the desired resistance was achieved with a mean of $5.9 \mathrm{~mL}$ bone cement injection, and there was a recurrent collapse in a vertebra into which they had injected $2.5 \mathrm{~mL}$ bone cement. Cheng-Ta et $\mathrm{al}^{23}$ reported that $4 \mathrm{~mL}$ of cement is adequate to reduce pain and achieve a good clinical outcome. Better clinical outcomes have been reported with high-viscosity cements. In our study, 3 to $6.5 \mathrm{~mL}$ of PMMA was injected to each vertebral body. Radiopaque bone cement with high viscosity was used throughout our series. Complications associated with PVP are observed at varying rates. The most important step is radiological examinations. Monitoring the cement application step by step with the help of imaging and injecting the cement when it reaches the proper viscosity are helpful in preventing leaks. Complications are most commonly caused when PMMA leaks out of the vertebral body, which has a rate of 2 to $73 \%$ depending on the level. ${ }^{24}$ Generally, cement leakage has been reported in 65\% of PVP cases $(30-73 \%)^{25,26}$ Leaks from metastatic vertebrae are more common than those from osteoporotic vertebrae and may occur in up to $85.7 \%$ of cases..$^{27,28}$ Schmidt et al..$^{29}$ determined the rate of bone cement leaks as 66 to $74 \%$. Vasconselos et $\mathrm{al}^{30}$ reported complications in $25.4 \%$ of the cases in their series. They reported that $16.6 \%$ of the leaks were cement leakage into paravertebral venous structures, and $8.8 \%$ were leaks into the intervertebral disc space. In our study, complications occurred in $18.8 \%$ of the cases in total. Leaks to paravertebral venous structures were the most common complication with a rate of $7.5 \%$. Leaks into the intervertebral disc space were observed in $6.6 \%$, those into paravertebral soft tissue were observed in $1.9 \%$, and those into subcutaneous soft tissue were observed in $1.9 \%$. Pulmonary cement embolism was observed in one case ( $0.9 \%$ ). However, no symptoms were found during and after the procedures. Leakage into the spinal canal was not observed. In general, the most important step in reducing cement leakage and development of complications is to evaluate the patient well before the PVP procedure. The more vertebral heigh loss, the more severe osteoporosis, the greater vascularity in the metastatic mass that causes collapse in the vertebral body, and complication development rates may increase. To briefly explain, the PMMA amount and fluidity are important. Proper use of the chuck in the bone filler device lumen during PMMA injection reduces complications associated with cement leakage. The vertebral body becomes more stable with PVP. Pain is reduced significantly after PVP. Pain is relieved due to the destruction of the interosseous nociceptors. ${ }^{31}$ The VAS scoring system is an indicator of post-PVP treatment efficacy. Grados et al reported that VAS scores dropped from 8.0 to 3.7 on average in the first month following the procedure. ${ }^{32}$ Zoarski et al, ${ }^{33} \mathrm{McGraw}$ et $\mathrm{al},{ }^{34}$ and Peh et $\mathrm{a}^{35}$ stated in their studies that there was a significant decrease in pain after PVP. In our study, the mean VAS score was 8.39 before PVP and 2.05 after PVP. In the unipedicular approach, the mean VAS score dropped to 2.3, and in the bipedicular approach, it dropped to 1.84 . There was a statistically significant reduction in the VAS scores after the PVP procedure in comparison to before PVP $(p<0.001)$. There was no statistically significant difference between the unipedicular and bipedicular approaches regarding pain reduction $(p>0.05)$. Considering cost and labor as well as radiation exposure, the unipedicular approach is generally sufficient in PVP operations.

\section{Conclusion}

PVP is an easy, reliable, and effective method for benign and malignant VCFs. It significantly relieves pain caused by VCFs. It should be used more frequently. PVP procedures will be implemented more comfortably in the future, as practitioners improve their experience with the help of enhanced PVP materials in use in addition to new and more equipped imaging devices and application techniques. We believe that, with the help of up-to-date imaging methods, besides PVP, other procedures for vertebrae, intervertebral discs, and paravertebral soft tissues (such as spinal radiofrequency ablation, posterior stabilization, and discectomy) will be performed more reliably in the near future.

\section{Note}

All procedures performed in studies involving human participants were in accordance with the ethical standards of the institutional and/or national research committee and with the 1964 Helsinki Declaration and its later amendments or comparable ethical standards.

Informed consent was obtained from all individual participants included in the study.

Consent for publication was obtained for every individual person's data included in the study.

This study was approved by the Research Ethics Board of Uludag University July 20, 2010, No. 2010-5/12.

\section{Conflict of Interest}

None declared. 


\section{Acknowledgment}

The authors would like thank Prof. Hakyemez for his contribution.

\section{References}

1 Johnell O, Kanis J. Epidemiology of osteoporotic fractures. Osteoporos Int 2005;16(Suppl 2) :S3-S7

2 Mut M, Schiff D, Shaffrey ME. Metastasis to nervous system: spinal epidural and intramedullary metastases. J Neurooncol 2005;75(1):43-56

3 Wong DA, Fornasier VL, MacNab I. Spinal metastases: the obvious, the occult, and the impostors. Spine 1990;15(1):1-4

4 Watts NB, Harris ST, Genant HK. Treatment of painful osteoporotic vertebral fractures with percutaneous vertebroplasty or kyphoplasty. Osteoporos Int 2001;12(6):429-437

5 Bostrom MP, Lane JM. Future directions. Augmentation of osteoporotic vertebral bodies. Spine 1997;22 (24 Suppl):38S-42S

6 Cooper C, Atkinson EJ, O'Fallon WM, Melton LJ III. Incidence of clinically diagnosed vertebral fractures: a population-based study in Rochester, Minnesota, 1985-1989. J Bone Miner Res 1992;7(2):221-227

7 Truumees E, Hilibrand A, Vaccaro AR. Percutaneous vertebral augmentation. Spine J 2004;4(2):218-229

8 Genant HK, Wu CY, van Kuijk C, Nevitt MC. Vertebral fracture assessment using a semiquantitative technique. J Bone Miner Res 1993;8(9):1137-1148

9 Logas WG, el-Baz N, el-Ganzouri A, et al. Continuous thoracic epidural analgesia for postoperative pain relief following thoracotomy: a randomized prospective study. Anesthesiology 1987;67(5):787-791

10 Watanabe S, Koyama K. Visual analogue pain scale with convenient digitizer. Anesthesiology 1989;71(3):481-482

11 Gracely RH, Methods of testing pain mechanisms in normal man. In: Wall PD, Melzack R, eds. Textbook of Pain. Singapore: Churchill Livingstone; 1989257

12 Benyamin R, Vallejo R. Vertebroplasty. Tech Reg Anesth Pain Manage 2005;9:62-67

13 McKiernan F, Faciszewski T, Jensen R. Quality of life following vertebroplasty. J Bone Joint Surg Am 2004;86(12):2600-2606

14 Cook DJ, Guyatt GH, Adachi JD, et al. Quality of life issues in women with vertebral fractures due to osteoporosis. Arthritis Rheum 1993;36(6):750-756

15 Silverman SL. The clinical consequences of vertebral compression fracture. Bone 1992;13(Suppl 2):S27-S31

16 Yeom JS, Kim WJ, Choy WS, Lee CK, Chang BS, Kang JW. Leakage of cement in percutaneous transpedicular vertebroplasty for painful osteoporotic compression fractures. J Bone Joint Surg Br 2003;85(1):83-89

17 Hide IG, Gangi A. Percutaneous vertebroplasty: history, techniqueand currentperspectives.ClinRadiol2004;59(6):461-467

18 Jensen ME, Evans AJ, Mathis JM, Kallmes DF, Cloft HJ, Dion JE. Percutaneous polymethylmethacrylate vertebroplasty in the treatment of osteoporotic vertebral body compression fractures: technical aspects. AJNR Am J Neuroradiol 1997;18(10):1897-1904

19 Tohmeh AG, Mathis JM, Fenton DC, Levine AM, Belkoff SM. Biomechanical efficacy of unipedicular versus bipedicular vertebroplasty for the management of osteoporotic compression fractures. Spine 1999;24(17):1772-1776

20 Cotten A, Dewatre F, Cortet B, et al. Percutaneous vertebroplasty for osteolytic metastases and myeloma: effects of the percentage of lesion filling and the leakage of methyl methacrylate at clinical follow-up. Radiology 1996;200(2):525-530

21 Mehbod A, Aunoble S, Le Huec JC. Vertebroplasty for osteoporotic spine fracture: prevention and treatment. Eur Spine J 2003;12(Suppl 2) :S155-S162

22 Heini PF, Wälchli B, Berlemann U. Percutaneous transpedicular vertebroplasty with PMMA: operative technique and early results. A prospective study for the treatment of osteoporotic compression fractures. Eur Spine J 2000;9(5):445-450

23 Cheng-Ta H, Jui-Ming S, Shih-Youeng C, Ming-Ying L, Da-Tong J. Pain relief in patients treated with percutaneous vertebroplasty: an evaluation cement volume. J Neurol Sci 2008;25:266-271

24 Padovani B, Kasriel O, Brunner P, Peretti-Viton P. Pulmonary embolism caused by acrylic cement: a rare complication of percutaneous vertebroplasty. Am J Neuroradiol 1999;20(3):375-377

25 Linville DA II. Vertebroplasty and kyphoplasty. South Med J 2002;95(6):583-587

26 Phillips FM, Todd Wetzel F, Lieberman I, Campbell-Hupp M. An in vivo comparison of the potential for extravertebral cement leak after vertebroplasty and kyphoplasty. Spine 2002;27(19):2173-2178

27 Mousavi P, Roth S, Finkelstein J, Cheung G, Whyne C. Volumetric quantification of cement leakage following percutaneous vertebroplasty in metastatic and osteoporotic vertebrae. J Neurosurg 2003;99(1, Suppl):56-59

28 Ratliff J, Nguyen T, Heiss J. Root and spinal cord compression from methylmethacrylate vertebroplasty. Spine 2001;26(13):E300-E302

29 Schmidt R, Cakir B, Mattes T, Wegener M, Puhl W, Richter M. Cement leakage during vertebroplasty: an underestimated problem? Eur Spine J 2005;14(5):466-473

30 Vasconcelos C, Gailloud P, Beauchamp NJ, Heck DV, Murphy KJ Is percutaneous vertebroplasty without pretreatment venography safe? Evaluation of 205 consecutives procedures. AJNR Am J Neuroradiol 2002;23(6):913-917

31 Rao RD, Singrakhia MD. Painful osteoporotic vertebral fracture. Pathogenesis, evaluation, and roles of vertebroplasty and kyphoplasty in its management. J Bone Joint Surg Am 2003;85(10):2010-2022

32 Grados F, Depriester C, Cayrolle G, Hardy N, Deramond H, Fardellone P. Long-term observations of vertebral osteoporotic fractures treated by percutaneous vertebroplasty. Rheumatology (Oxford) 2000;39(12):1410-1414

33 Zoarski GH, Snow P, Olan WJ, et al. Percutaneous vertebroplasty for osteoporotic compression fractures: quantitative prospective evaluation of long-term outcomes. J Vasc Interv Radiol 2002;13(2 Pt 1) :139-148

34 McGraw JK, Lippert JA, Minkus KD, Rami PM, Davis TM, Budzik RF. Prospective evaluation of pain relief in 100 patients undergoing percutaneous vertebroplasty: results and follow-up. J Vasc Interv Radiol 2002;13(9 Pt 1):883-886

35 Peh WC, Gilula LA, Peck DD. Percutaneous vertebroplasty for severe osteoporotic vertebral body compression fractures. Radiology 2002;223(1):121-126 